TITLE:

\title{
Wear behavior of diamond wheel for grinding optical connector ferrule - FEA and wear test -
}

$\operatorname{AUTHOR}(S)$ :

Suh, Chang-Min; Bae, Kyo-Seouk; Suh, Min-Soo

\section{CITATION:}

Suh, Chang-Min ...[et al]. Wear behavior of diamond wheel for grinding optical connector ferrule - FEA and wear test -. Journal of Mechanical Science and Technology 2008, 22(11): 2009-2015

ISSUE DATE:

2008-11

URL:

http://hdl.handle.net/2433/134581

\section{RIGHT:}

The final publication is available at www.springerlink.com; This is not the published version. Please cite only the published version.; この論文 は出版社版でありません。引用の際には出版社版をご確認ご利用くだ さい。 


\title{
WEAR BEHAVIOR AND DIAMOND CONCENTRATION OF DIAMOND WHEEL FOR GRINDING OPTICAL CONNECTOR FERRULE -THE FEA AND WEAR TEST
}

\author{
Chang-Min Suh ${ }^{\mathrm{a}}$, Kyo-Seouk Bae ${ }^{\mathrm{b}}$ and Min-soo Suh ${ }^{\mathrm{c}, *}$ \\ ${ }^{a}$ School of Mechanical Engineering, Kyungpook National University, 1370 Sankyuk-dong, Buk-gu, 702-701, \\ Daegu, Republic of Korea \\ ${ }^{\mathrm{b}}$ Graduate School of Mechanical Engineering, Kyungpook National University, 1370 Sankyuk-dong, Buk- \\ gu, 702-701, Daegu, Republic of Korea \\ ${ }^{\mathrm{c}}$ Graduate School of Energy Science, Kyoto University, Gokasho, Uji, 611-0011, Kyoto, Japan
}

E-mail: mssuh@iae.kyoto-u.ac.jp

\begin{abstract}
The grinding characteristics and the wear behavior of diamond wheel for grinding the optical connector ferrule were investigated by finite element analysis (FEA) and wear test. FEA of contact between diamond wheel and ferrule shows that the subsurface damage area of ferrule is $13 \mu \mathrm{m}$ from the interface of abrasive particle and matrix. Fallout of abrasive particles is affected by the stress state at this interface. A 2-D finite element model was established to calculate the distribution of stress at the interface. As the result of FEA, fallout condition of abrasive was concerned with the ratio of critical protrusion; the ratio of particle size is about 0.6. FE model was established to investigate the effects of the diamond concentration of wheel. The FEA result shows that the lower concentration has the larger wear volume due to the small stress propagation. To investigate grinding performance, the pin-on-disc wear test was carried out for three types of diamond concentrations $75 \%, 100 \%$ and $125 \%$. Through the wear test, it was confirmed that the $75 \%$ wheel concentration has the highest amount of wear volume. This result shows good agreement with that of FEA. And $100 \%$ concentration, by considering the grinding ratio, shows the best optimized result for the grinding performance.
\end{abstract}

KEYWORDS: Energy science, Ferrule, FEA (Finite Element Analysis), Diamond wheel, Concentration, Wear, Grinding, Sliding friction, Pin-on-disc

*Corresponding author. Tel.: +81 77438 3465; fax: +81 774383467.

E-mail address: mssuh@iae.kyoto-u.ac.jp (M.-S. Suh).

\section{INTRODUCTION}


Grinding with bound abrasives has been extensively used in forming and finishing components of many materials [1-5]. The demand of parts associated with the advanced optical technology is increasing due to the growth and the expansion of the optical industry. Especially, super-precision optical parts associated with IT, NT and BT requires the high anti-deviation to accomplish the ultra precision machining. The wear characteristics of ceramic materials and cutting tools are important factor to control the precision of the products, and it is widely studied by many researchers: e.g. mechanisms of material removal in grinding ceramics [6,7], grinding of silicon nitride [8-10], energy concerns with grinding [11-14], and by relating the grinding forces and energy to various parameters associated with the undeformed chip geometry $[15,16]$.

The understanding of the behavior of both the matrix and the diamond abrasives becomes important, due to the wide use of diamond tool [17-20]. The severe wear and/or fracture of the diamond wheel are a restriction to mass production; grinding process includes a sacrifice not only the workpiece but also the diamond wheel. The objective of this study is to investigate the wear characteristics of the ceramic ferrule grinding by the diamond wheel.

The ultra-high technology is necessary to perform precision machining of hard machining material such as ceramics.

In this study, the FE method was used to analyze the stress distribution and the abrasive at the contact area of the ferrule. The wear test was performed to verify the FEA results and to find the optimal condition of grinding from the comparison of each results.

\section{THEORETICAL BACKGROUND}

\subsection{Cutting point spacing}

The successive cutting point spacing and the contact arc length are necessary for creating the FE model by considering the concentration. First of all, the contact arc length, $1_{c}$, is formulated in kinematics of surface grinding, as shown in Eq. (1).

$$
l_{c}=\left(1+\frac{v}{V}\right) \sqrt{\frac{\Delta}{\frac{1}{D}+\frac{1}{d}}}
$$

where, $\mathrm{v}$ is the workpiece velocity $[\mathrm{rpm}] \mathrm{V}$ is the wheel velocity [rpm], $\Delta$ is the cutting depth $[\mu \mathrm{m}]$, $\mathrm{d}$ is the workpiece diameter [mm] and $\mathrm{D}$ is the wheel diameter [mm].

Theoretical successive cutting point spacing, $a_{t h}$ is calculated by Eq. (2).

$$
a_{t h}=\frac{2 d_{g}}{3 V_{g}}
$$


where, $d_{g}$ is the equivalent diameter [mm] when the abrasive is assumed as sphere and $V_{g}$ is the ratio of abrasive particles.

\subsection{Grinding force for single abrasive}

The Merchant's theory was used to evaluate the specific grinding energy of a single abrasive to create the FE model as a micro element of the grinding wheel. Fallout of an abrasive is mainly affected by tangential grinding force. The value of tangential grinding force was $2.31 \times 10^{-4} \mathrm{~N}$. This value was set up on the load condition of the FE model.

\subsection{Grinding force acting on the abrasive}

Shaw model [21] was used in this study. Applying the Shaw model to the FE model, the diamond shape particle was converted into the sphere which has a diameter of $20 \mu \mathrm{m}$ and the frictional force

was neglected. Tangential grinding force was considered as a direct relationship with the fallout of abrasives.

\subsection{Specific wear rate and grinding ratio}

Wear of the wheel is related to the amount of grinding. Inverse value of the specific wear rate is grinding ratio, $\mathrm{G}$ as shown in Eq. (3).

$$
G=T / S
$$

where $\mathrm{T}$ is the wear volume of material and $\mathrm{S}$ is the wear volume of wheel.

The parameter $\mathrm{G}$ was evaluated to use as a standard of the economical efficiency of the diamond wheel.

\section{CHARACTERISTICS OF MATERIALS}

\subsection{Characteristics of the zirconia ferrule}

TZP (Tetragonal Zirconia Polycrystal) was used in this study as the test material. It has been using widely in broad industry because of the excellence in hardness, strength/weight ratio, thermal stability, and corrosion resistance. 


\subsection{Characteristics of the diamond wheel}

Table 1 shows the material properties of a diamond and a resin, which is the specification of the diamond wheel. In case of machining the ferrule, the diamond wheel which is made by a phenolic resin is used; it has relatively high elasticity but low grinding resistance. Phenolic resin can bring a high revolution and a high grinding amount due to a proper removing flash and scale. Generally the phenolic resin is used but fiber reinforced phenolic resin is also used in special demand. Elastic modulus of the diamond wheel applied in FE simulation was $46 \mathrm{GPa}$ which was determined by an elastic modulus of grade, $\mathrm{N}$.

Table 1 Material properties and specification of the diamond wheel

\begin{tabular}{lcc}
\hline Properties & Diamond & Resin \\
\hline Elastic Modulus (GPa) & 1171 & 7 \\
Poisson's ratio & 0.1 & 0.3 \\
Concentration & $100 \%$ & \\
Mesh \# (abrasive size) & $\# 400(40 \mu \mathrm{m})$ \\
Grade & $\mathrm{N}(46 \mathrm{GPa})$ \\
Outer diameter & $60 \mathrm{~mm}$ \\
Inner diameter & $20 \mathrm{~mm}$ \\
Thickness & $5 \mathrm{~mm}$ \\
\hline
\end{tabular}

\section{FINITE ELEMENT ANALYSIS}

\subsection{Contact analysis between wheel and ferrule}

\subsubsection{Finite element model}

The interacting surface, where the grinding area is minutely divided by 4-node rectangular plane of strain elements, is to generate the most accurate gradient for the stress which is large at this area. 
Motion of the model was described as the wheel and ferrule has a relative rotations and the ferrule was fed into the wheel. In this analysis, the cutting depth was set as one tenth of the real cutting depth for analyzing the contact instant. Time duration was set as $1 \mathrm{~ms}$. During at $0.4 \mathrm{~ms}$, the ferrule was moved in front of the diamond wheel, and during at another $0.3 \mathrm{~ms}$, the grinding was processed. The rest of the time, the grinding process has ended. In this analysis, the stick-slip friction model was used at the interface of the wheel and ferrule.

\subsubsection{Result of finite element analysis}

Fig. 1 shows the stress variations at the interface of the wheel and ferrule for the depth from the contact point. Ferrule stress exceeded its own flexural strength, $1 \mathrm{GPa}$, after the contact duration at $0.1 \mathrm{~ms}$. After this moment, the grinding process has been begun rapidly by the fracture propagation of the ferrule.

Fig. 2 shows the distributions of the von Mises stresses of the wheel and ferrule for the depth from the contact point. The greatest amplitude of stress was located on the contact point and the amplitude of stress was decreased as the increase of depth from the contact point. The stress converges under the flexural strength under $100 \mu \mathrm{m}$ depths from the contact point. The stress at the area, under about $63 \mu \mathrm{m}$ depth from the surface, has exceeded the flexural strength of $1 \mathrm{GPa}$. The estimated subsurface damage was about $13 \mu \mathrm{m}$ except for the cutting depth of $50 \mu \mathrm{m}$.

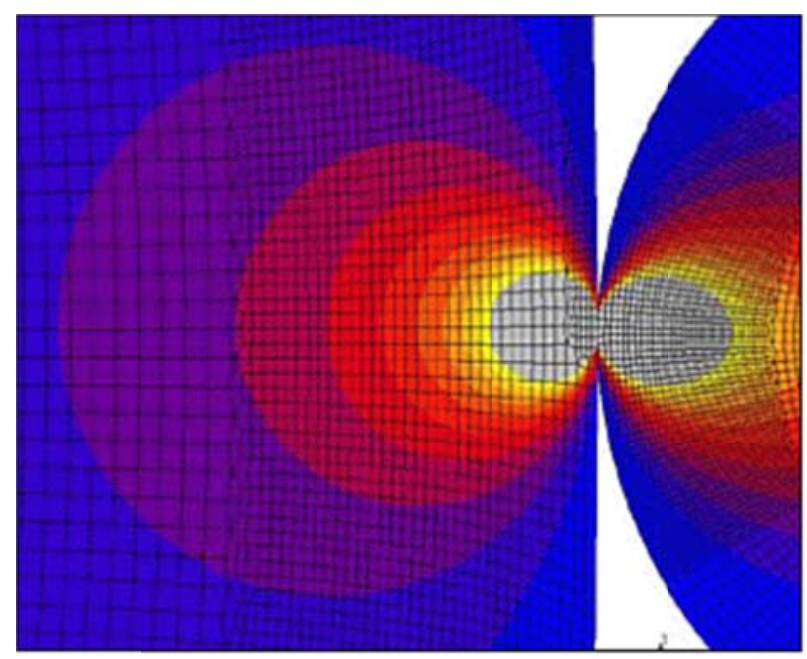

Fig. 1 Magnified distribution of von Mises stress at the contact interface 


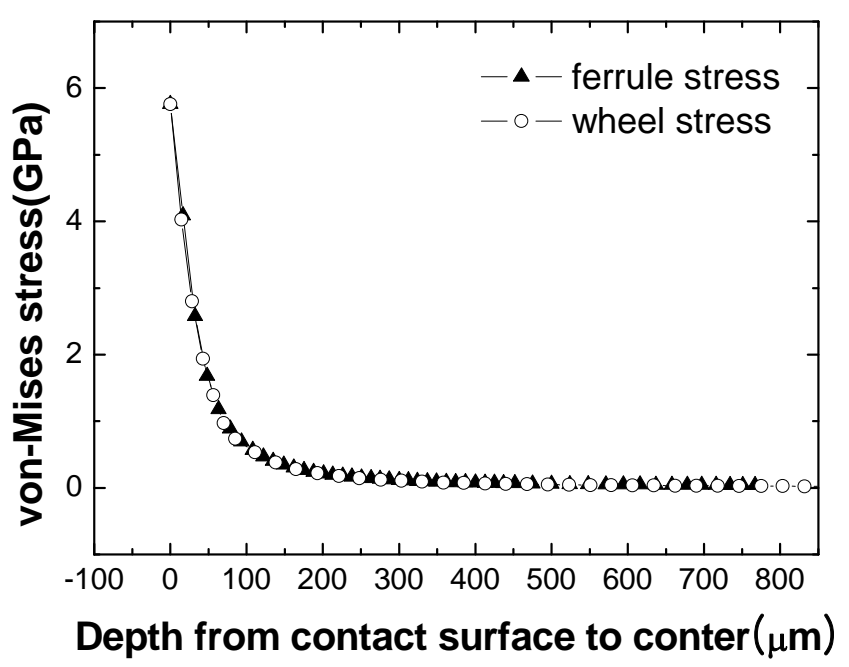

Fig. 2 von Mises stress of ferrule and wheel versus the depth from contact surface

\subsection{Interface analysis between abrasive and resin}

\subsubsection{Finite element model}

Normal force and frictional force were generated by the relative motion of the abrasive and workpiece. These forces will generate the stress at the contact interface between abrasive and resin. This state of stress is determined by the load and wear amount of the abrasive (Zhou, 1997). Semiinfinite matrix model was created, which has 600 times larger size than real diamond abrasive. The stick-slip condition was selected as the boundary condition of the contact interface.

\subsubsection{Finite element model for the wear mechanisms}

Three types of assumptions for models were used as wear mechanisms in this analysis. Three models in this study: a symmetric wear, the symmetrical wear before the diamond particle detached; an asymmetric wear, wear occurs only in one side around the resin of the diamond particle and the other side remains; and a particle wear, wear amount of abrasive is relatively higher than that of resin.

\subsubsection{Result of finite element analysis}

Fig. 3 shows the stress distribution of all models. Fig. 3 (b) and (d) shows the moment just before the fallout of the abrasive. The stress concentration occurred at the corner of the particle. The stress 
concentration has the greatest value, especially at the root of the particle. The stress concentration was increased at the root of the particle as the wear progressed in both case of the wear, symmetric and the asymmetric. The stress at the interface of the resin and particle was higher than the stress at the particle tip, which directly applied to the grinding force. The ratio of the uncovered and covered part which led the fallout of abrasive is about 0.6 and it corresponds with other paper (Zhou, 1997).

Fig. 4 shows the stress distribution of the interface for the particle wear. The characteristics of each specimen after and before the tests are listed in Table 3. In case of the particle wear, the stress amplitude is three or four times larger than the cases of symmetric and asymmetric wear. The smaller stress of the interface between the abrasive and resin was, therefore, estimated at the root of the abrasive. In this case, it can be estimated that the wheel have to perform the dressing process.

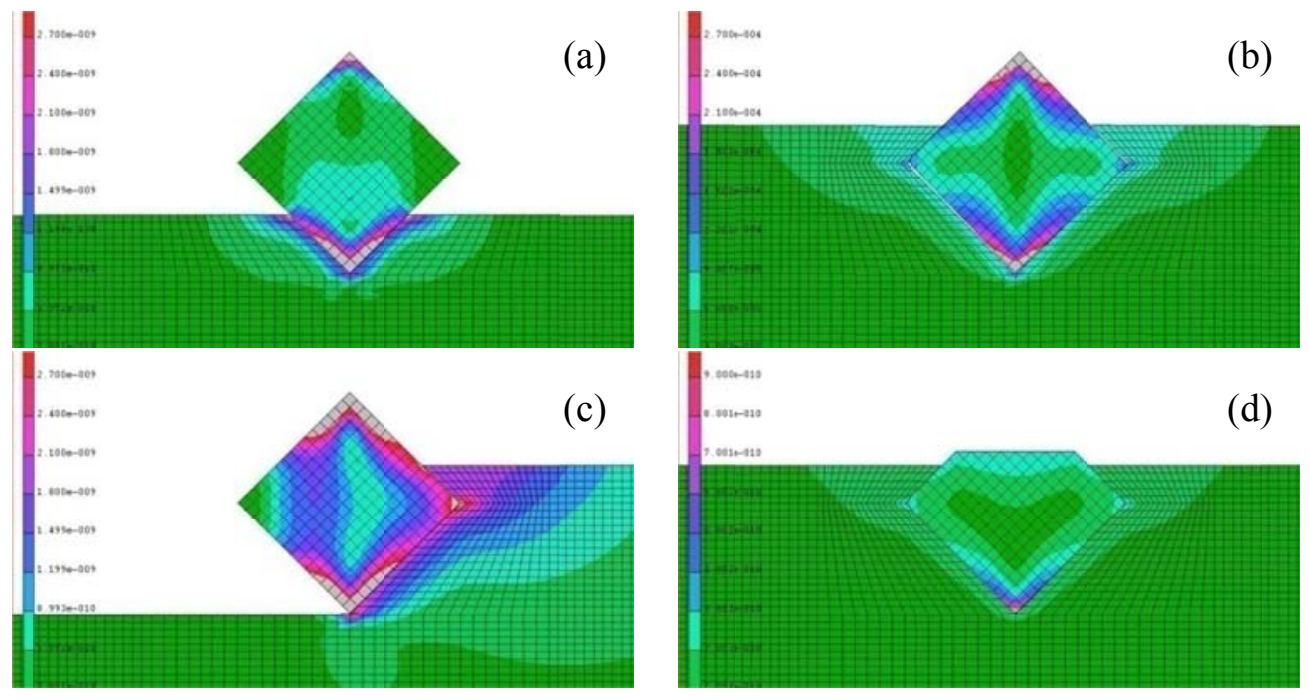

Fig. 3 Four kinds of stress distribution for the interface of abrasive and resin (a) no wear (b) symmetric wear. (c) asymmetric wear (d) particle wear

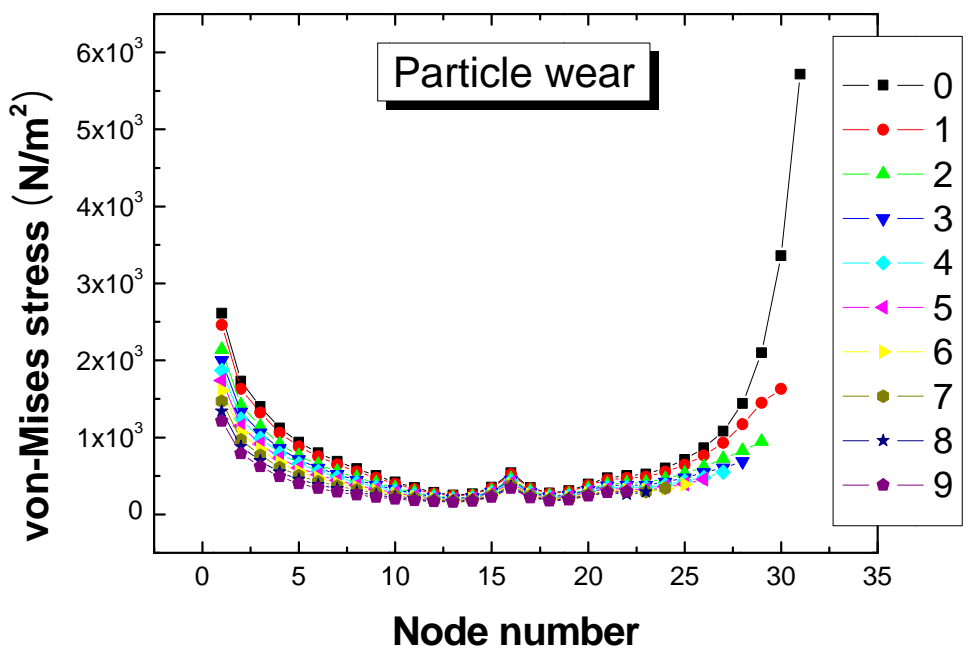


Fig. 4 von Mises stress versus node number in case of particle wear

Table 2 Grinding ratio and wear volume of the ferrule and diamond wheel

\begin{tabular}{cccccc}
\hline & $\begin{array}{c}\text { Length of ferrule Length of wheel } \\
\text { before test }\end{array}$ & after test & $\begin{array}{c}\text { Wear volume of } \\
\text { ferrule }\end{array}$ & $\begin{array}{c}\text { Wear volume of } \\
\text { wheel }\end{array}$ & $\begin{array}{c}\text { Grinding ratio, } \\
\text { G }\end{array}$ \\
\hline $1-1$ & 10.47 & 7.81 & 52.18 & 0.62 & 80.03 \\
$1-2$ & 10.47 & 6.27 & 82.40 & 0.83 & 98.84 \\
$1-3$ & 10.48 & 7.95 & 49.63 & 0.50 & 99.49 \\
$2-1$ & 10.48 & 7.33 & 61.80 & 0.77 & 80.24 \\
$2-2$ & 10.46 & 6.38 & 80.04 & 0.73 & 109.54 \\
$2-3$ & 10.45 & 7.57 & 56.50 & 0.63 & 89.38 \\
$3-1$ & 10.46 & 6.93 & 69.25 & 0.76 & 91.15 \\
$3-2$ & 10.46 & 6.13 & 84.95 & 0.68 & 125.73 \\
$3-3$ & 10.46 & 7.78 & 52.58 & 0.58 & 94.21 \\
\hline
\end{tabular}

\subsection{Analysis for the diamond concentration of wheel}

\subsubsection{Finite element model}

The diamond concentration was used as a parameter for the evaluation. The grinding wheel consists of abrasive, resin and void. The role of void is to collect the chip; mainly affects on the discharge of the chip. Table 3 shows the successive cutting point spacing of the three different concentrations which was derived by the Eq. (2), and the ratio of the abrasive for the concentration. In each case, diamond concentration has the number of abrasive particles $75 \%$ has $4 ; 100 \%$ has 5 ; and $125 \%$ has 6. Contact arc length, calculated by Eq. (1), was $374 \mu \mathrm{m}$ and is applied to the model. There are two constraint conditions one is $\mathrm{x}$ direction at two side edges and the other is $\mathrm{y}$ direction at the bottom of the model. 
Table 3 Three models of diamond concentration of wheel

\begin{tabular}{ccc}
\hline Concentration & $\mathrm{V}_{\mathrm{g}}$ (ratio of abrasive particles) & $\mathrm{a}_{\mathrm{th}}$ \\
\hline $75 \%$ & 0.1875 & 96.0 \\
$100 \%$ & 0.5200 & 72.0 \\
$125 \%$ & 0.3125 & 57.6 \\
\hline
\end{tabular}

\subsubsection{Result of finite element analysis}

The equivalent strain distribution of $100 \%$ concentration is shown in Fig. 5. The distributions of the strain are similar to the distributions of stress except for abrasives. The tensile side of the matrix, which applied the grinding force and the side edge, has a greater strain. This is caused by the stress concentration at the side edge. The larger the concentration is, the larger the strain occurred.

In case of the $75 \%$ concentration, the border strain of the first particle is larger than the second one where the minimum value of the strain located closely. The phenomenon of $125 \%$ concentration, similar to $100 \%$, was the opposite of $75 \%$ concentration. In case of the low concentration, the space among the particles is far from each other so the influence between the particles hardly existed. Consequently, the strain of the first particle was relatively large and widely distributed due to the grinding force acting on the first diamond particle was larger than any other ones. In case of the $100 \%$ concentration, the interaction between the first and second particle is not negligible because of the space among the particles was, naturally, closer than $75 \%$.

Because of the influence among the abrasive particles, the strain has increased as the increase of concentration; the stress has decreased. The stress at the interface of the matrix and abrasive has relaxed according to the increase of the concentration. It can be easily presumed that the factor of the abrasive fallout becomes weaken by the increasing of the concentration.

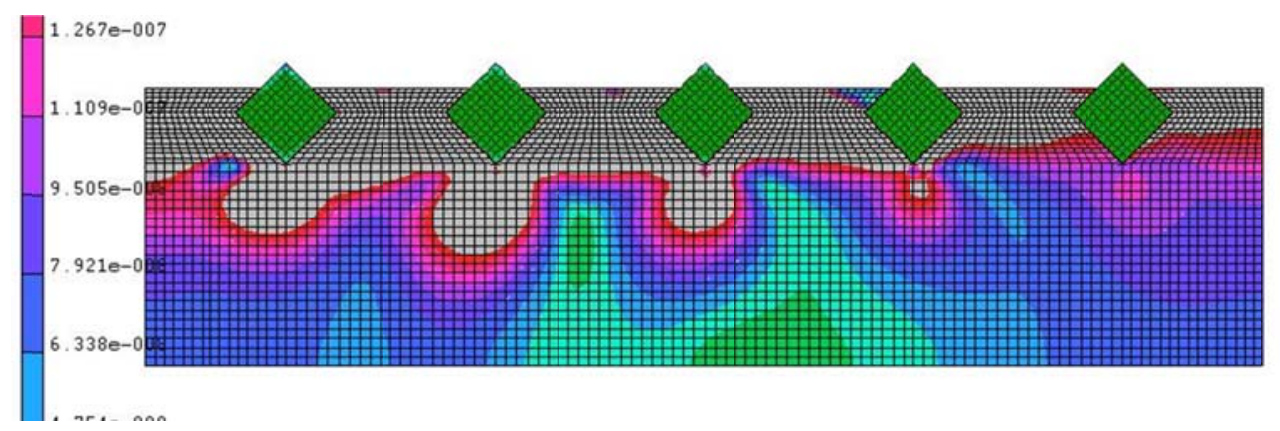

Fig. 5 Strain distribution according to the $100 \%$ concentration of the diamond wheel 


\section{WEAR TEST}

\subsection{Result of wear test}

The pin-on-disc wear test was performed for diamond wheels which has different concentrations. The atmosphere was in-air temperature, unlubricated. The coefficient of friction was in the range of 0.44 to 0.46 , in all test condition. In other words, it can verify that the unstable wear behavior has not occurred during the test. Fig. 6 shows the wear volumes of the ferrule and the diamond wheel. The wear volume of diamond wheel was too small that the data is expressed decupled as shown in Fig. 6. The wear volume of the $75 \%$ concentration was the largest in all other sets except for the first set (shown in Fig. 7). The higher the diamond concentration is, the smaller wear of wheel occur. In case of the $100 \%$ concentration, the ferrule has the largest wear volume. It looks like that the self-sharpening occurred but the glazing or loading has hardly occurred.

Fig. 7 shows the grinding ratio of each test set. In case of $100 \%$, it has the highest grinding ratio. In case of $75 \%$, on the other hand, it has the lowest grinding ratio. And in the case of $125 \%$, it was presumed to have the highest the grinding ratio due to the smallest wear volume but the wear volume of grinding wheel and also the removed amount of ferrule was small. When the small grinding depth and force was processed, the $125 \%$ diamond concentration may well be fitted.

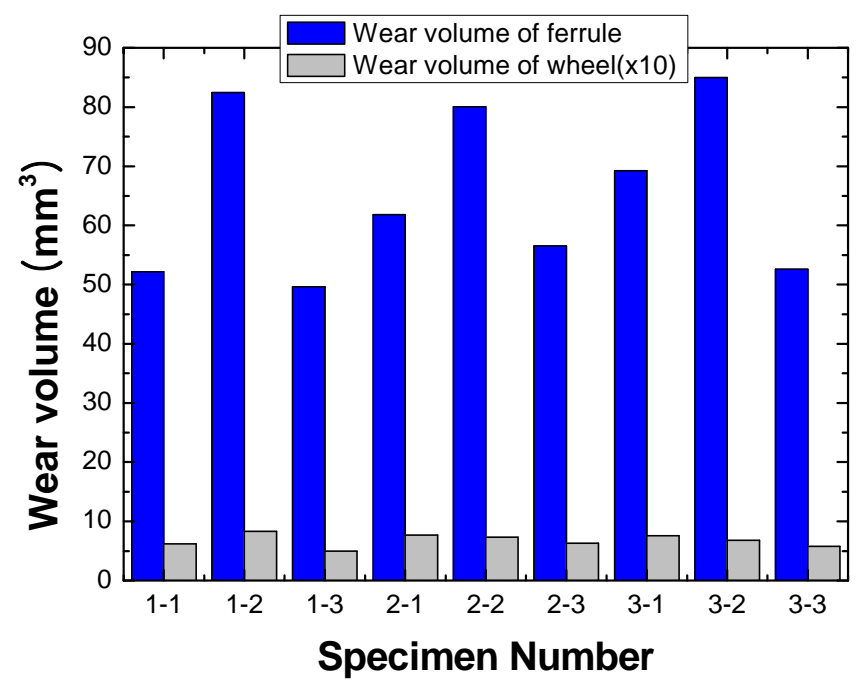

Fig. 6 Bar chart of the wear volume of ferrule and wheel 


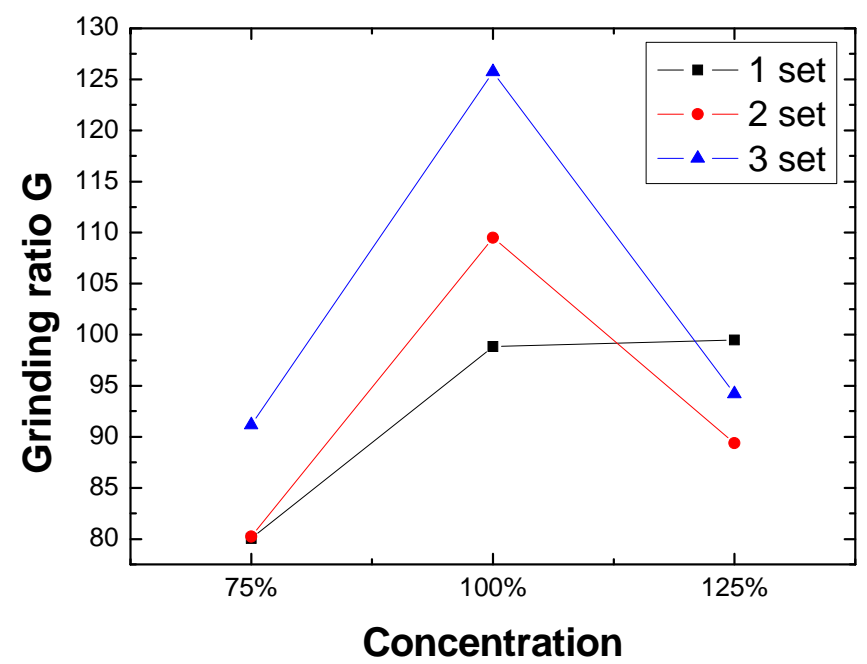

Fig. 7 Variation of grinding ratio, $\mathrm{G}$ versus concentration ratio

\subsection{Microscopic observation of wear surface}

Fig. 8 shows a SEM photograph of the sectional view that diamond wheel of $75 \%$ concentration. A void, that many particles are shed in the resin, can be seen as $\mathrm{V}$ mark. A solid line indicates an interface of the surface and section of the diamond wheel. The traces of the particles fall out can be observed. In case of the wear test, the diamond (marked as D) wheel has the concentration of $125 \%$; the traces of the particles fall out have not been observed, and the grinding face has flat surface. If the grinding face became as the flat surface, the grinding resistance will be increased. And then, the wear occurred in the processing face of ferrule and wheel. Thus the quality of the ground face of ferrule becomes low. 


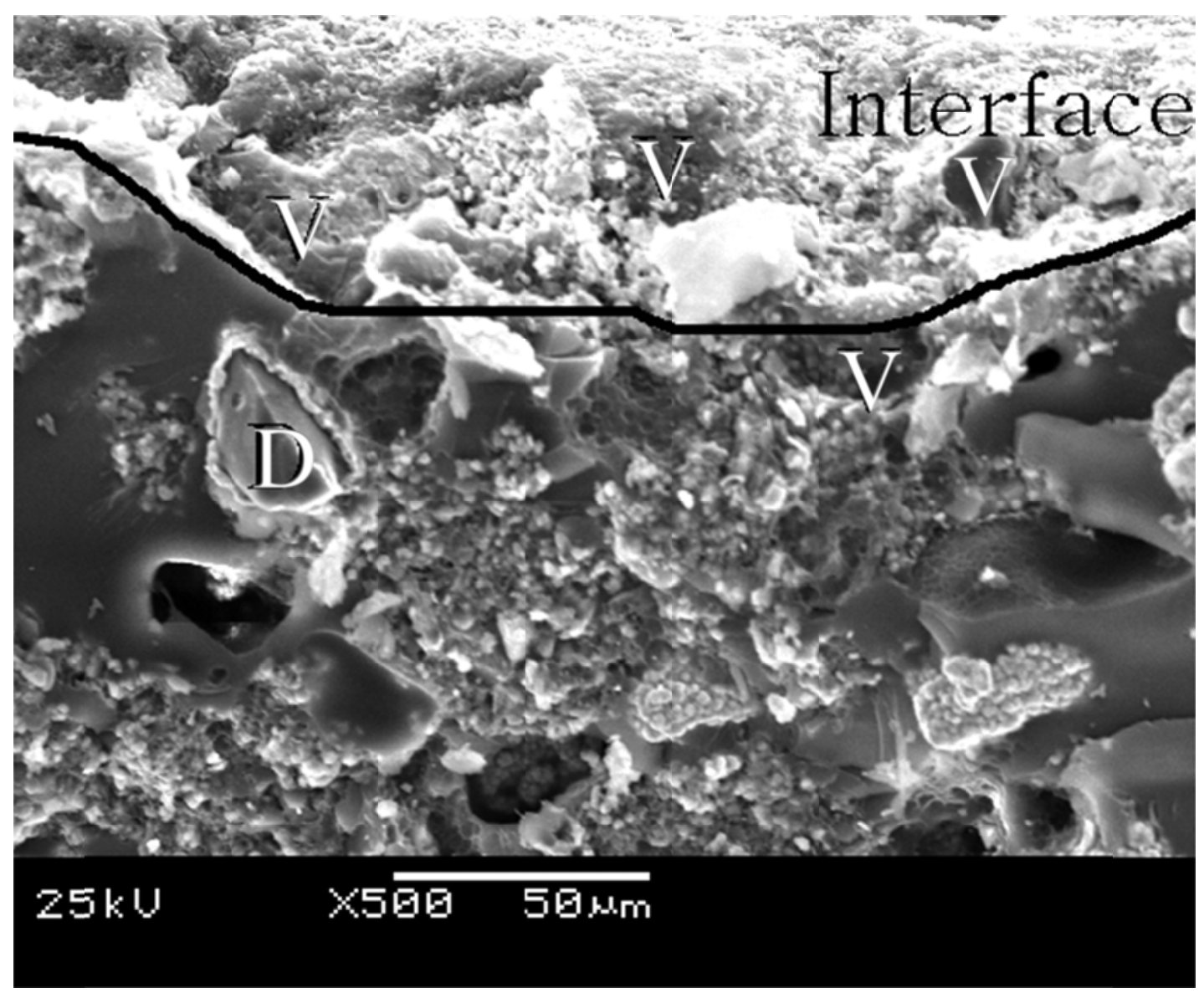

Fig. 8 SEM photograph of $75 \%$ concentration wheel $(\times 500)$, V: void, and D: diamond particle

\section{CONCLUSIONS}

The result of contact analysis shows that the area of subsurface damage was $13 \mu \mathrm{m}$ when the depth of cutting was $50 \mu \mathrm{m}$.

The result of interface analysis shows that the abrasive fallout condition is the ratio of the critical protrusion; the fallout of abrasive particle is about 0.6 .

The result of FEA according to concentration, the lower diamond concentration has the higher stress concentration due to the lower interactive among the abrasives particles. Abrasive fallout is, therefore, faster and the wear of the diamond wheel is propagated rapidly. These results are well corresponded with the result of the wear test. These results were also confirmed by the SEM observation.

The optimal condition of the diamond concentration is $100 \%$ and the worst condition is $75 \%$. 


\section{Acknowledges}

This research was supported by the Program for Training of Graduate Student in Regional Innovation which was conducted by the Korea Industrial Technology Foundation and the Ministry of Commerce, Industry and Energy of the Korean Government

\section{REFERENCES}

[1] Peter Blake, Thomas Bifano, Thomas Dow, Ronald O Scattergood, "Precision Machining of Ceramic Materials", American Ceramic Society Bulletin 67 (6) (1988)1038-1041

[2] S. Malkin, J. E. Ritter, "Grinding Mechanisms and Strength Degradation for Ceramics", Journal of Engineering for Industry, (1989) 167-174

[3] S. Malkin, Grinding Technology-Theory and Applications of Machining with Abrasives, Ch. I, Ellis Horwood, Chichester, 1989, pp.9-17

[4] J.L. Mertzger, Super abrasive Grinding, Ch. 1, Butterworth, Oxford, 1986, pp. 3-11

[5] Y. Zhou, P.D. Funkenbusch, D.J. Quesnel, "Stress Distribution at the Abrasives-matrix Interface during Tool Wear in Bound Abrasive Grinding-Finite Element Analysis", Wear 209 (1997) 247 254

[6] Bi. Zhang, Howes, D. Trevor, "Material-removal mechanisms in grinding ceramics", CIRP Annals - Manufacturing Technology 43 (1) (1994) 305-308

[7] S. Malkin, and T.W. Hwang, "Grinding Mechanisms for Ceramics," Ann. CIRP, 45 (2) (1996) $569-580$

[8] T.W. Hwang, C.J. Evans, S. Malkin, "Size effect for specific energy in grinding of silicon nitride", Wear 225-229 (PART II) (1999) 862-867

[9] T.W. Hwang, C.J. Evans, E.P. Whitenton, S. Malkin, "High speed grinding of silicon nitride with electroplated diamond wheels, part 1: Wear and wheel life", Journal of Manufacturing Science and Engineering, Transactions of the ASME 122 (1) (2000) 32-41

[10] T.W. Hwang, C.J. Evans, S. Malkin, "High Speed Grinding of Silicon Nitride With Electroplated Diamond Wheels, Part 2: Wheel Topography and Grinding Mechanisms", Journal of Manufacturing Science and Engineering, Transactions of the ASME 122 (1) (2000) 42-50

[11] S. Malkin, N. Joseph, "Minimum Energy in Abrasive Processes", Wear 32 (1), (1975) 15-23

[12] T.W. Hwang, S. Malkin, "Upper bound analysis for specific energy in grinding of ceramics", Wear 231 (2) (1999) 161-171

[13] S. Malkin, "Correlation between Solid Particle Erosion of Metals and Their Melting Energies", Wear 68 (3) (1981) 391-396

[14] G.N. Shah, A.C. Bell, S. Malkin, "Quantitative Characterization of Abrasive Surfaces Using a New Profile Measuring System”, Wear 41 (2) (1977)315-325

[15] C. Chen, Y. Jung, and I. Inasaki, "Surface, Cylindrical and Internal Grinding of Advanced Ceramics", Grinding Fundamentals and Applications, PED-Vol. 39, ASME (1989) 201-211

[16] T.W. Hwang, and S. Malkin, "Grinding Mechanisms and Energy Balance for Ceramics", ASME J. Manuf. Sci. Eng., 121, (1999) 623-631 
[17] D. Miller, A. Ball, “The wear of diamonds in impregnated diamond bit drilling”, Wear 141 (1991) 311-320

[18] Y.S. Uao, S.Y. Luo, "Wear characteristics of sintered diamond composite during circular swing", Wear 157 (1992) 325-337

[19] X. Tian, S. Tian, "The wear mechanisms of impregnated diamond bits", Wear 177 (1994) 81-91

[20] W. Konig, A. Neises, "Wear mechanisms of ultrahard, non-metallic cutting materials", Wear 162/164 (1993) 12-21

[21] M.C Shaw, "New Theory of Grinding”, Inst Eng Aust. Mech. Chem. Eng Trans MC8 (1) (1972) $73-78$ 